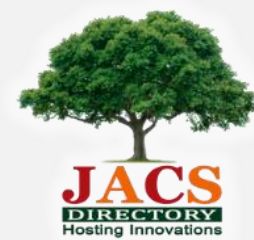

Journal of Nanoscience and Technology

\author{
Visit Journal at http://www.jacsdirectory.com/jnst
}

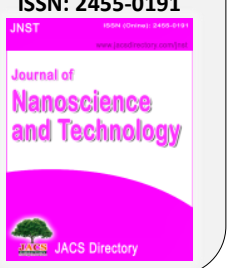

Special Issue on "International Conference on Advanced Materials and Their Applications"

Issue Editor: Dr. C. Vedhi

\title{
Synthesis and Characterization of CdS/Polypyrrole Core/Shell Nanocomposites with Controlled Grain Size
}

\author{
G. Selva Manohari1,2,*, M. Daniel Sweetlin ${ }^{3}$ \\ ${ }^{1}$ Research Scholar (Reg. No. 18221272132004), Department of Physics, St. John's College, Palayamkottai, affiliated to Manonmaniam Sundaranar \\ University, Abishekapatti, Tirunelveli - 627 012, Tamilnadu, India. \\ ${ }^{2} P G$ \& Research Department of Chemistry, V.O. Chidambaram College, Thoothukudi - 628 012, Tamilnadu, India. \\ ${ }^{3}$ Department of Physics, St. John's College, Palayamkottai - 627 002, Tamilnadu, India.
}

\section{ART ICLE DETAILS}

Article history:

Received 20 March 2019

Accepted 29 April 2019

Available online 04 June 2019

\section{Keywords:}

Core/Shell

Nanocomposites

Cadmium Sulfide

Polypyrrole

\begin{abstract}
A B S T R A C T
Many challenges of core/shell nanostructures for various applications still exist. The structure including the diameter, length, spacing and the thickness of the core or shell is difficult to control precisely. Metal nanoparticles used as various types of catalysts adsorbents and sensors. They have applications in optical, electronic and magnetic devices. Majority of these applications significantly depend on the size of the nanoparticles. Therefore, the synthesis of nanoparticles with controlled grain size is important. In the present work, Cadmium sulfide (CdS) was used as the core material which coated by the polypyrrole (PPy). To form the core and the shell set, the diameter fixed and measured theoretically. The calculated amount is used to prepare the shell which is formed by addition polymerization. The XRD studies are used to determine the particle size of the core shell nanocomposite. The average particle size of CdS and CdS/PPy is $13 \mathrm{~nm}$ and $15 \mathrm{~nm}$ respectively. Fourier transform infrared (FTIR) spectra and UV-Vis spectra are used to characterize the structure and to calculate the band gap of the core/shell nanocomposite. The AFM studies give the surface morphology of the samples.
\end{abstract}

\section{Introduction}

Scientists have discovered that certain classes of polymers called conjugated polymers, which contain many double bonds in their structure, are actually semi-conductors with unusual electrical properties. Numerous studies have been performed on the conjugated polymers, such as polypyrrole, polyaniline, polythiophene and polyphenylene etc., [1]. Polypyrrole is an inherently conductive polymer due to interchain hopping of electrons. The monomer pyrrole is a heterocyclic aromatic organic compound, a five membered ring with formula $\mathrm{C}_{4} \mathrm{H}_{4} \mathrm{NH}$. It has very low basicity compared to amines and other aromatic compounds like pyrridine, wherein the ring is not bonded to a hydrogen atom. This decreased basicity is attributed to the lone pair of electrons of the nitrogen atom in the aromatic ring. PPy has higher conductivity than polyaniline and is easy to be synthesized. Moreover, it has relatively high air-stability and water-stability [2]. Semiconducting optoelectronic materials play functional role in variety of applications due to their extraordinary optical, electrical, magnetic and piezoelectric properties. Modifications of the optical, electrical, magnetic and physical properties of semiconductor materials strictly depend upon the sizes, structures and morphologies [3]. Cadmium sulfide (CdS) is a brilliant II-VI semiconductor material with a direct band gap of $2.42 \mathrm{eV}$ at room temperature with many outstanding physical and chemical properties, which has promising applications in multiple technical fields including photochemical catalysis, gas sensor, detectors for laser and infrared, solar cells, nonlinear optical materials, various luminescence devices, optoelectronic devices and so on. CdS has excellent visible light detecting properties among the others semiconductors [4]. Surface coating of nanoparticles with different materials to produce core/shell structure is an active area of research, since such coating allows modification and tailoring of physical and chemical properties of core materials depending on synthesis conditions [5]. In this present work, the core material CdS was synthesized by simple wet chemical method and coated by polypyrrole in nanolevel.

\section{Experimental Methods}

\subsection{Synthesis of $C d S$}

Cadmium sulphate and thiourea were used as precursors. The CdS nanoparticle was prepared by mixing cadmium sulphate and thiourea in $0.01 \mathrm{M}$ concentration. Both are dissolved in water. $0.01 \mathrm{M}$ solution of thiourea was prepared by dissolving $0.0386 \mathrm{~g}$ in $50 \mathrm{~mL}$ of water. This solution was added to ammonium hydroxide solution to maintain the $\mathrm{pH}$ 13. $0.01 \mathrm{M}$ solution of cadmium sulphate $\left(0.384 \mathrm{~g}\right.$ in $\left.50 \mathrm{~mL} \mathrm{of} \mathrm{H}_{2} \mathrm{O}\right)$ was prepared and the solution was added to the thiourea solution and stirred for 15 minutes. Stirring process was undertaken the solution for proper mixing of both solutions. Then the solution was heated for 1 hour. The yellow colour precipitate was obtained which contains fine particle of CdS [6]. The obtained product was filtered and washed thoroughly three times with distilled water, and then the sample was air dried and weighed.

\subsection{Synthesis of Polypyrrole}

The ratio of the pyrrole monomer and the oxidant is fixed as $1: 2.0 .03 \mathrm{M}$ solution of pyrrole $\left(0.1038 \mathrm{~g}\right.$ in $50 \mathrm{~mL}$ of $\left.\mathrm{H}_{2} \mathrm{O}\right)$ was added to the $0.06 \mathrm{M}$ solution of ammonium persulfate $\left(0.6846 \mathrm{~g}\right.$ in $50 \mathrm{~mL}$ of $\left.\mathrm{H}_{2} \mathrm{O}\right)$ and the reaction mixture was stirred continuously for 2 hours at $10^{\circ} \mathrm{C}$, to obtain conducting polypyrrole. The obtained polypyrrole was filtered and washed with water and dried at $60^{\circ} \mathrm{C}$ in an oven $[7,8]$. The yield of the PPy was also calculated.

\subsection{Synthesis of CdS/Polypyrrole}

Average diameter of CdS was $13 \mathrm{~nm}$ obtained from the XRD result. In this method the core material added during polymerization. The thickness of the shell $(2 \mathrm{~nm})$ fixed and the corresponding weight of the core calculated. $0.03 \mathrm{M}$ solution of pyrrole added to the $0.06 \mathrm{M}$ solution of ammonium persulfate and the reaction mixture stirred continuously at the room temperature. When the reaction mixture solution colour gets changed, the calculated amount of as prepared cadmium sulfide powder $(0.099 \mathrm{~g})$ was added. The stirring process was carried out for 3 hours at a constant temperature $10^{\circ} \mathrm{C}$. The obtained composites filtered and washed with distilled water and then dried at $60^{\circ} \mathrm{C}$. 


\section{Results and Discussion}

\subsection{X-Ray Diffraction Study}

The XRD patterns of the samples CdS, polypyrrole and CdS/PPy nanocomposite are shown in Fig. 1. The X-ray diffraction pattern for CdS displays four intense peaks. The values agree well with the standard value for CdS (JCPDS Card No. 10 - 454). Thus, the XRD peaks can be identified as $2 \theta$ at $26.966^{\circ}(111), 43.851^{\circ}(220), 51.96^{\circ}$ (311) peaks for cubic Z-type structure [9-12]. The average particle size of CdS is $13 \mathrm{~nm}$. The XRD pattern of polypyrrole indicates its poor crystalline nature. A broad band is noticed in the region of $15^{\circ}<2 \theta<30^{\circ}$ with the broad peak maximum around $24^{\circ}$ which is marked by a solid line. The XRD pattern reveals that the obtained polypyrrole is amorphous material [13]. The XRD pattern of CdS/PPy nanocomposite displays six peaks which is matches well with the standard values for cadmium sulfide (JCPDS Card No. 41-1049) with reduced intensity [14]. Reduced intensity is due to the over coating of PPy. Along with the sharp peaks, broad peak also presents at around $24^{\circ}$. The average particle size of the composites is $15 \mathrm{~nm}$. It confirms the presence of CdS and polypyrrole in the nanocomposite. The particle sizes are calculated using Scherrer formula which is shown in Table 1.
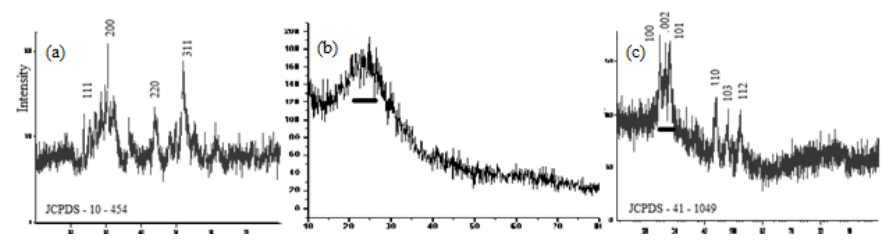

Fig. 1 XRD pattern of (a) CdS, (b) PPy and (c) CdS/PPy nanocomposite

Unit cell software is used to calculate the lattice parameter and cell volume which is shown in Table 2 . It reveals that the structure of core material changed from cubic to hexagonal during the formation of core/shell nanostructure. The cell volume decreases due to quantum confinement effect.

Table 1 Average particle size

\begin{tabular}{lllll}
\hline Sample & $\begin{array}{l}\text { Observed } \\
2 \theta(\mathrm{deg})\end{array}$ & $\begin{array}{l}\text { FWHM } \\
\text { (Radians) }\end{array}$ & $\begin{array}{l}\text { Grain Size } \\
(\mathrm{nm})\end{array}$ & $\begin{array}{l}\text { Average grain } \\
\text { size }(\mathrm{nm})\end{array}$ \\
\hline CdS & 26.9663 & 0.5353 & 15.33 & \\
& 43.8519 & 0.5353 & 16.71 & $13.33(13)$ \\
& 51.9604 & 0.9368 & 9.46 & \\
CdS/PPy & 25.0775 & 0.6691 & 12.17 & \\
& 26.7322 & 0.5353 & 15.32 & $14.52(15)$ \\
& 44.0842 & 0.5353 & 16.08 & \\
\hline
\end{tabular}

Table 2 Lattice parameters

\begin{tabular}{llll}
\hline Sample & Cell Constant $(\AA)$ & Cell Volume $(\AA)$ & Structure \\
\hline CdS & $\mathrm{a}=5.8374$ & 198.9064 & Cubic \\
CdS/PPy & $\mathrm{a}=4.10394 ; \mathrm{c}=6.66551$ & 97.2221 & Hexagonal \\
\hline
\end{tabular}

\subsection{FTIR Studies}

The FTIR spectrum of the samples CdS, PPy and CdS/PPy are shown in Fig. 2. FTIR is very useful to identify the functional groups presence in PPy as well as in the nanocomposite [15].

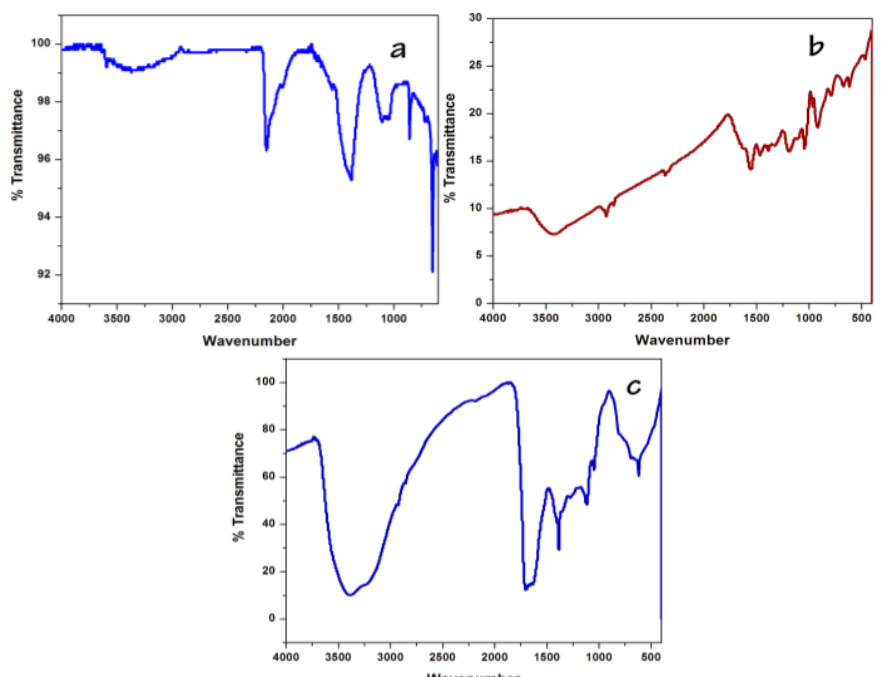

Fig. 2 FTIR spectra of (a) CdS, (b) PPy and (c) CdS/PPy nanocomposite https://doi.org/10.30799/jnst.S09.19050306
In Fig. 2(a) show peaks at $1104 \mathrm{~cm}^{-1}$ and $650 \mathrm{~cm}^{-1}$ due to the presence of metal sulfide [16]. Fig. 2(b) shows that the band at $3395 \mathrm{~cm}^{-1}$ corresponds to N-H stretching. The bands at $2921 \mathrm{~cm}^{-1}$ and $2852 \mathrm{~cm}^{-1}$ may due to the $\mathrm{C}-\mathrm{H}$ stretching. The peak observed around $1629 \mathrm{~cm}^{-1}$ for the $\mathrm{C}=\mathrm{C}$ stretching. The bands at $1382 \mathrm{~cm}^{-1}$ and $1196 \mathrm{~cm}^{-1}$ due to $=\mathrm{C}-\mathrm{H}$ in-plane bending, while the peaks at $791 \mathrm{~cm}^{-1}$ and $929 \mathrm{~cm}^{-1}$ are due to $=\mathrm{C}-\mathrm{H}$ out of plane vibration (Ring deformation). The peak observed at $1045 \mathrm{~cm}^{-1}$ in for the $\mathrm{C}$ - $\mathrm{H}$ vibration of 2, 5 substituted pyrroles [7]. From the FTIR spectrum, it confirmed that the material is pure polypyrrole. The spectrum of $\mathrm{CdS} / \mathrm{PPy}$ confirms that the sample contains polypyrrole as well as the metal sulfide ions, which is consistent with the result of the XRD analysis.

\subsection{UV-Visible Studies}

UV-Vis spectrum studies help to found the absorbance of the samples. And it also helps to found the optical band gap energy of the materials. One may estimate a value for the band gap from a tauc plot of $(\alpha \mathrm{hv})^{2}$ against the photon energy. CdS is a direct band gap material, with absorption edge for the bulk hexagonal CdS is at $512 \mathrm{~nm}$ which has the band gap energy 2.4 $\mathrm{eV}$. The calculated band gap is $2.62 \mathrm{eV}$. The higher band gaps compared to the bulk energy gap $(2.42 \mathrm{eV})$ are consistent with the quantum confinement effects of CdS nanoparticles. The optical bandgap of conducting polypyrrole and core/shell nanocomposite are $2.81 \mathrm{eV}$ and $3.02 \mathrm{eV}$ respectively. In a semiconductor the most important consequence of the confinement effect is an increase in the band gap energy [17], which is confirmed by the obtained result.
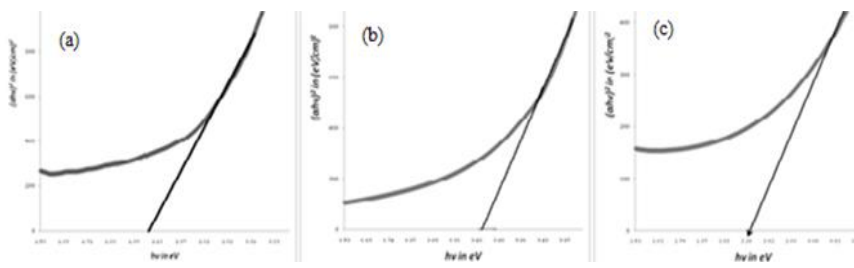

Fig. 3 Tauc plot for (a) CdS, (b) PPy and (c) PPy nanocomposite

Table 3 Bandgap values

\begin{tabular}{ll}
\hline Materials & Bandgap in $\mathrm{eV}$ \\
\hline CdS & 2.62 \\
PPy & 2.81 \\
CdS/PPy & 3.02 \\
\hline
\end{tabular}
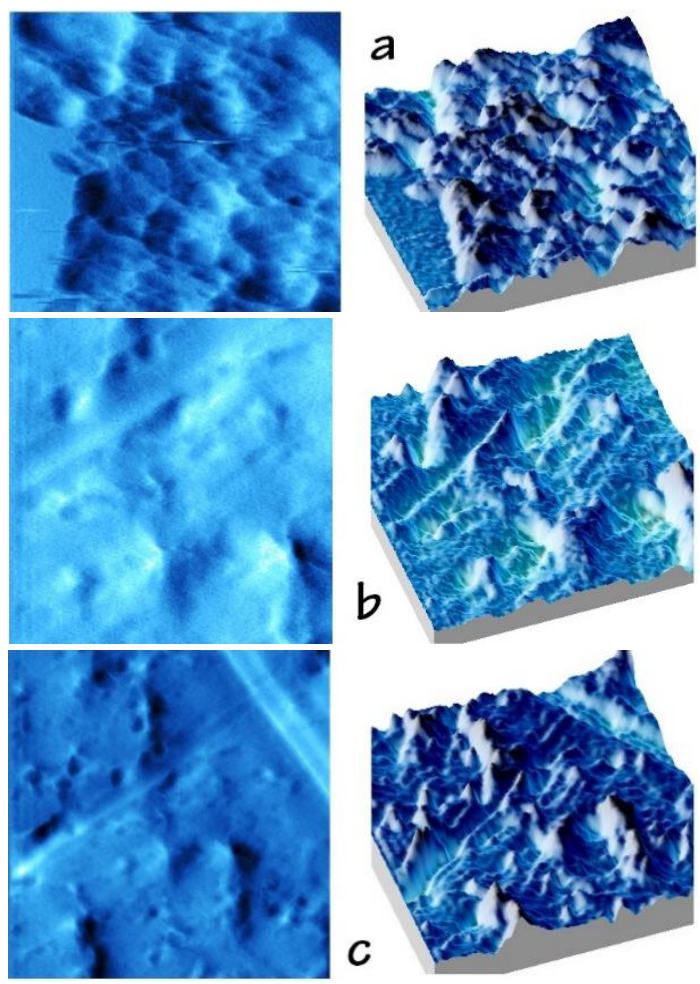

Fig. 4 AFM micrographs of (a) CdS, (b) PPy and (c) PPy nanocomposite

\subsection{AFM Studies}

Atomic force microscopy is a powerful surface analytical technique used in air, liquid or vacuum to generate very high-resolution 
topographic images of a surface down to molecular/atomic resolution. Depending on the sharpness of the tip it gives spatial resolutions of 1-20 nm. Fig. 4 shows that the topography of CdS, PPy and CdS/PPy nanocomposites respectively. An AFM study reveals that the surface appears more nodular with oriented lines. Some very deep valleys were clearly visible on the AFM images.

\section{Conclusion}

In the present work, pure cadmium sulphide and polyprrole were successfully synthesized by simple wet chemical method and addition polymerization method respectively. CdS/PPy core/shell nanocomposite was synthesized by in-situ polymerization method with the desired shell thickness $(2 \mathrm{~nm})$. The XRD studies show that the obtained composite has core/shell nanostructure. The FTIR studies confirm the presence of the $\mathrm{CdS}$ and polypyrrole in the core/shell nanocomposite. The optical bandgap of the materials calculated using the UV-Vis spectrum. Increase of the bandgap value is due to the confinement effect. The AFM studies give the morphology of the material. From the above results, one can synthesize the core/shell nanocomposite with controlled grain size.

\section{References}

[1] N.I. Bohari, Z.A. Talib, M.A. Syafiq, M. Yunos, A. Kassim, Synthesis and characterization on electrical properties of conducting polymer of polypyrrole and polypyrrole/cadmium sulfide composites, Int. J. Phys. Sci. 7(10) (2012) 1670-1676.

[2] Shu Zhand, Q. Chen, Y. Wang, L. Guo, Synthesis and photoactivity of CdS photocatalysts modified by polypyrrole, Int. J. Hyd. Energy 37 (2012) 30303036.

[3] Ziaul Raza Khan, M. Zulfequar, M. Shahid Khan, Chemical synthesis of CdS nanoparticles and their optical and dielectric studies, J. Mater. Sci. 46 (2011) 5412-5416.
[4] C. Burda, X. Chen, R. Narayanan, M.A. El-Sayed, Chemistry and properties of nanocrystals of different shapes, Chem. Rev. 105 (2005) 1025-1102.

[5] M. Maleki, M. Sasani Ghamsari, S. Mirdamadi, R. Ghasemzadeh, A facile route for preparation of CdS nanoparticles, Semicond. Phys. Quantum Electron. Optoelect.10 (2007) 30-32.

[6] A.G. MacDiarmid, Synthetic Metals: A Novel Role for Organic Polymers, Angew. Chem. 40 (2001) 2581-2590.

[7] Anuar Kassim, Zarinabte Basar, H.N.M. Ekramul Mahmud, Effects of preparation temperature on the conductivity of polypyrrole conducting polymer, Proc. Indian Acad. Sci. (Chem. Sci.) 114 (2002) 155-162.

[8] L.B. Sorensen, J.O. Cross, Resonance anomalous X-ray scattering, Elseries, Amsterdam, 1994.

[9] A.B. Bially, R. Seoudi, W. Eisa, A.A.Shabaka, S.I. Soliman, R.K.A Hamid, R.A. Ramadan, Preparation, characterization and physical properties of CdS nanoparticles with different sizes, J. Appl. Sci. Res. 8 (2012) 676-685.

[10] B Girginer, G. Galli, E. Chiellini, N. Bicak, Preparation of stable CdS nanoparticles in aqueous medium and their hydrogen generation efficiencies in photolysis of water, Int. J. Hyd. Energy 34 (2009) 1176-1184.

[11] R.J. Bandaranayake, G.W. Wen, J.Y. Lin, H.X. Jiang, C.M. Sorensen, Structural phase behavior in II-VI semiconductor nanoparticles, Appl. Phys. Lett. 67 (1995) 831-833.

[12] L.L. Ma, H.Z. Sun, Y.G. Zhang, Y.L. Lin, J.L. Li, et al., Preparation, characterization and photocatalytic properties of CdS nanoparticles dotted on the surface of carbon nanotubes, Nanotechnol. 19 (2008) 115709:1-8.

[13] Shengyu Jing, Shuangxi Xing, Chun Zhao, Direct synthesis of PbS/polypyrrole core-shell nanocomposites based on octahedrak $\mathrm{PbS}$ nanocrystals colloid, Mater. Lett. 62 (2008) 41-43.

14] S.C. Hernandez, D. Chaudhuri, W. Chen, V. Nosang, Myung, A. Mulchandani, Single polypyrrole nanowire ammonia gas sensor, Electroanal. 19 (2007) 2125-2130.

[15] V. Jain, Organic spectroscopy, 1 ${ }^{\text {st }}$ Edn., IVY Publishing House, Delhi, 2002.

[16] W. Jaimes, G. Alvarado Tenorio, C. Martinez Alonso, A. Quevedo Lopez, H. Hu, M.E. Niicho, Effect of CdS nanoparticle content on the in-situ polymerization of 3-hexylthiophene-2,5-diyl and the application of P3HT-CdS products in hybrid solar cells, Mater. Sci. Semicond. Proces. 37 (2015) 259-265.

[17] P.F. Trwoga, A.J. Kenyon, C.W. Pitt, Modeling the contribution of quantum confinement to luminescence from silicon nanoclusters, J. Appl. Phys. 83(7) (1998) 3789-3794.

\section{About the Conference...}

"International Conference on Advanced Materials and Their Applications" has been convened by Dr. C. Vedhi, Assistant Professor, PG and Research Department of Chemistry, V.O. Chidambaram College, Thoothukudi at his designated venue on $27^{\text {th }}$ December 2018. 